\title{
Decoding Circadian Rhythm and Epileptic Activities: Clues From Animal Studies
}

\author{
Cenglin $\mathrm{Xu}^{1,2+}$, Jie $\mathrm{Yu}^{1+}$, Yeping Ruan ${ }^{1}$, Yi Wang ${ }^{1,2}$ and Zhong Chen ${ }^{1,2 *}$ \\ ${ }^{1}$ College of Pharmaceutical Science, Zhejiang Chinese Medical University, Hangzhou, China, ${ }^{2}$ NHC and CAMS Key \\ Laboratory of Medical Neurobiology, College of Pharmaceutical Sciences, Institute of Pharmacology and Toxicology, Zhejiang \\ University, Hangzhou, China
}

The relationship between circadian rhythm and epilepsy has been recognized for decades. Yet many questions underlying the complex mechanisms of their interaction remain elusive. A better understanding on this topic allows the development of accurate seizure-detection algorithm and alternative precise therapeutic strategies. Preclinical laboratory studies based on epileptic animal models, with controllable epileptogenic pathology and an array of intervention strategies, shed light on the bidirectional effects between circadian rhythm and epileptic seizures as well as their underlying mechanisms.

OPEN ACCESS

Edited by:

Eliane Kobayashi,

McGill University, Canada

Reviewed by:

Maxime Lévesque,

McGill University, Canada

Steve Gibbs,

Université de Montréal, Canada

*Correspondence:

Zhong Chen

chenzhong@zju.edu.cn

tThese authors have contributed equally to this work

Specialty section: This article was submitted to

Epilepsy,

a section of the journa

Frontiers in Neurology

Received: 30 November 2019

Accepted: 18 June 2020

Published: 24 July 2020

Citation:

Xu C, Yu J, Ruan Y, Wang Y and Chen Z (2020) Decoding Circadian

Rhythm and Epileptic Activities: Clues From Animal Studies.

Front. Neurol. 11:751

doi: 10.3389/fneur.2020.00751
Here, we reviewed findings on the interaction between circadian rhythm and epileptic seizures in the preclinical setting. We present the possible mechanisms at molecular, cellular and circuitry levels. We propose that future experimental designs should take into account the relationship between circadian rhythm and epilepsy as well as the underlying mechanisms in different types of animal models, which may have a translational significance as stepping stones for clinical benefits.

Keywords: circadian rhythm, sleep, epilepsy, animal model, mechanism

\section{INTRODUCTION}

Circadian rhythm is one of the most basic rhythms in every organism, giving rise to our night-and-day variations in vital activities, especially mammals. The circadian rhythm can both physiologically and pathologically affect the brain in multiple aspects, among which the regulation of sleep/wake cycle (1-3) is considered the most important. Physiologically, the maintenance of sleep/wake rhythm, especially the ultradian rapid eye movement/non-rapid eye movement (REM/NREM) sleep cycle, is important for various daily activities in human beings. Pathologically, especially in epilepsy, the close relationship between circadian rhythm and epileptic activities has been recognized for years and emerges with an ever-increasing importance (4). On the one hand, epileptic activities are usually presented in a circadian pattern (5). A better understanding of the pattern would contribute to an accurate prediction of seizure onset and the development of closedloop treatments in the future $(6,7)$. On the other, the epileptogenic pathology might interfere with the normal circadian rhythm especially the sleep/wake cycle, thereby exerting a large impact on people's daily living and even resulting in severe consequences (8). Despite the great progress have been already achieved through clinical studies, our knowledge regarding the underlying mechanism of circadian rhythm and epilepsy remained far from adequate, mainly limited by the confounding factors in observational studies (such as genetic variations, anti-epileptic medications, and psychiatry comorbidities) (4). The limitation, however, could be well-circumvented by bench 
research using epileptic animal models and multifaceted intervention strategies, which provides valuable insights into the underlying mechanisms (9). In this review, we describe how did the circadian rhythm and epileptic activities influence each other based on evidence from laboratory studies employing different epileptic animal models. We summarize the possible mechanisms at the molecular, cellular and circuitry level. Lastly, the perspective with a translational insight are provided for a greater basic-clinical integration in the future.

\section{SLEEP ACTIVITY AND CIRCADIAN RHYTHM-DEPENDENT EPILEPTIC ACTIVITIES}

The circadian timing system in the human body regulates the timing of the sleep-wake cycle and modulates brain activities (10). Physiologically, the dynamic excitation-inhibition balance of brain network as well as the secretion of hormones such as cortisol or melatonin follows a circadian rhythm are both related with the sleep-wake cycle. Similarly, the epileptic brain also exhibits a day-and-night variation in its excitationinhibition balance, due to the different brain excitability in the active (mainly wakefulness) and inactive (mainly sleep) phases $(4,11)$.

\section{Sleep Activity Influences Seizure Susceptibility in Animal Models Kindling Models}

In animal studies, the different seizure susceptibility in sleep and wakefulness was first studied in kindling models. In 1982, Calvo et al. reported that rats receiving amygdaloid kindling stimulations during REM sleep had a delayed progression of kindling process than those receiving kindling stimulations during wakefulness (12). Another study examining the seizure susceptibility in light/dark phases also showed that electric induced seizure thresholds were higher in the dark phase compared with those in the light phase (13). This is further verified by Kumar et al, who showed that increasing the REM sleep resulted in a decreased seizure susceptibility in kindled rats (14). The influence of sleep activities on kindled seizure susceptibility was further studied using paradoxical sleep deprivation (PSD). In the 1980s, Shouse and his colleagues performed a series of experiments on amygdaloid kindled temporal lobe epilepsy (TLE) cats to study the effect of PSD on epileptic seizures. They found that the loss of both REM and NREM sleep caused by PSD could increase the seizure susceptibility (15-17).

\section{Other Epileptic Models}

The effect of sleep on seizure susceptibility is also verified on acute models. In 1988, Vale and Leite performed PSD on mice. Similar to kindled animals, this manipulation increased the susceptibility to pentylenetetrazol-induced acute seizures (18). PSD could also increase seizure activities in a genetically epileptic WAG/Rij rats. The number of spike-wave discharges increased during the early period of the 12 h-long PSD, and then returned to the baseline level (19).

Taken together, based on existing studies in different models, it has been shown that sleep patterns can directly modulate the susceptibility of seizures. Sleep deprivation, although may induce other many complex physiological changes, could increase seizure susceptibilities.

\section{Epileptic Seizures Occur With Circadian Rhythmicity in Chronic Models Chronic Temporal Lobe Epileptic Models}

As clinical studies suggested, most seizures occur in a temporal pattern following the circadian rhythm $(5,20,21)$. To further study the effect of circadian rhythm on epileptic seizures, chronic models of epilepsy were used. Unlike the models of acute seizures $(9,22)$, chronic models usually exhibit spontaneous recurrent seizures (SRS) after experiencing chemical convulsant or electrical stimulation induced status epilepticus (SE), which mimics the seizure presentation in patients (23-25). With the advent of digital technology, the development of long-term EEG recording contributed to an ever deeper understanding of the circadian pattern of epileptic seizures in chronic models of epilepsy. Relevant studies were also consecutively reported since the 1990s. Cavalheiro et al. reported that rats experiencing pilocarpine induced SE showed a higher seizure frequency in the light phase (26). Following that, a comparison study performed by Quigg et al. also demonstrated that seizures occurred more often during light phase in both rats and humans (27). The circadian distribution of spontaneous seizures was further reported in kainate acid or electrical stimulus induced chronic epileptic rats. Also in those studies, a higher possibility of seizure occurrence in the light phase were presented as well (28-32). Another study by Pitsch et al. further revealed a striking clustering of spontaneous seizures at the transition from the light to dark period in pilocarpine treated mice (33). Even after light deprivation, the occurrence of seizures still showed a circadian pattern (2). However, contradictory results exist as well, some studies reported that seizure frequency in pilocarpine-treated rats was unrelated to the circadian rhythm. The discrepancy might be due to the different age of animals used in different studies (34). Till now, we may conclude that the majority of findings, mostly from chronic TLE models, support a circadian distribution of seizures. Furthermore, seizure activities are more prominent in the light phase, which is the inactive period of rodents (Figure 1).

\section{Other Chronic Epileptic Models}

Apart from the classic chronic TLE models, experiments were carried out in other types of epileptic models which exhibited SRS as well $(35,36)$. Interestingly, the findings were contradictory to those in TLE models. Just as Stewart et al. proposed, in an atypical absence epilepsy model where absence seizures originate from the neocortex, the duration of seizure-like discharges reached two peaks at the onset of dark and light phase (35). The same group further studied this issue in an Aldh5a1 gene deficient epileptic mice. It is a gene encoding Mitochondrial $\mathrm{NAD}^{+}$-dependent succinate semialdehyde dehydrogenase [SSADH] enzyme that 


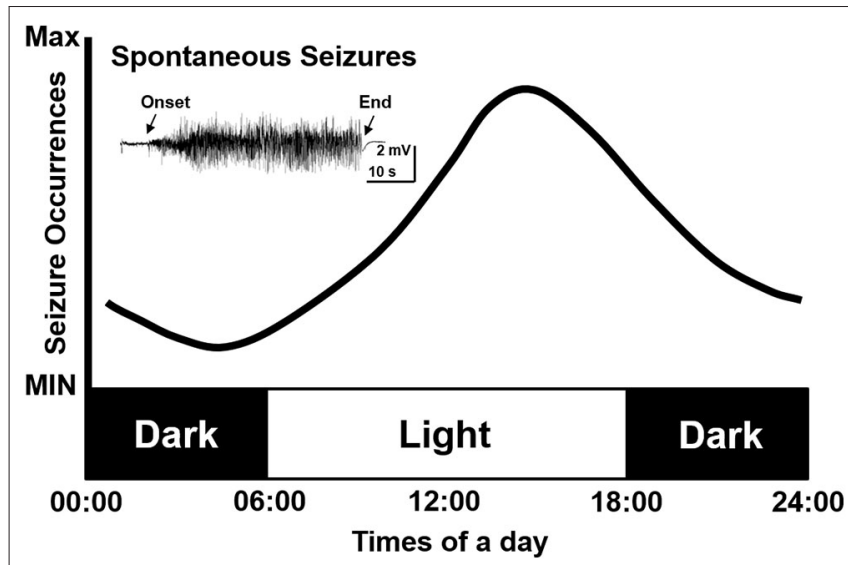

FIGURE 1 | Simulative circadian distribution of spontaneous recurrent seizures in chronic TLE models. The distribution of spontaneous recurrent seizures is not totally random in different phases but shows a circadian pattern in epileptic rodents. The seizures occur more often in the light phase.
TABLE 1 | Summary of circadian epileptic seizures in chronic TLE models.

\begin{tabular}{|c|c|c|c|c|}
\hline Studies & Model & Animals & $\begin{array}{l}\text { Circadian } \\
\text { seizures } \\
(\mathrm{Y} / \mathrm{N})\end{array}$ & $\begin{array}{l}\text { Seizure occurs } \\
\text { prominently in } \\
\text { which phase }\end{array}$ \\
\hline Cavalheiro et al. (26) & Pilocarpine & Rat & Yes & Light phase \\
\hline Quigg et al. (27) & $\begin{array}{l}\text { Electric } \\
\text { stimulus }\end{array}$ & Rat & Yes & Light phase \\
\hline $\begin{array}{l}\text { Hellier and Dudek } \\
\text { (31) }\end{array}$ & $\begin{array}{l}\text { Kainate } \\
\text { acid }\end{array}$ & Rat & Yes & Light phase \\
\hline Quigg et al. (28) & $\begin{array}{l}\text { Electric } \\
\text { stimulus }\end{array}$ & Rat & Yes & Light phase \\
\hline Raedt et al. (32) & $\begin{array}{l}\text { Kainate } \\
\text { acid }\end{array}$ & Rats & Yes & Light phase \\
\hline $\begin{array}{l}\text { Tchekalarova and } \\
\text { Pechlivanova (29) }\end{array}$ & $\begin{array}{l}\text { Kainate } \\
\text { acid }\end{array}$ & Rat & Yes & Light phase \\
\hline Bajorat et al. (34) & Pilocarpine & Rat & No & $\mathrm{N} / \mathrm{A}$ \\
\hline $\begin{array}{l}\text { Sedigh-Sarvestani } \\
\text { et al. (30) }\end{array}$ & $\begin{array}{l}\text { Tetanus } \\
\text { toxin }\end{array}$ & Rat & Yes & Light phase \\
\hline Pitsch et al. (33) & Pilocarpine & Mice & Yes & $\begin{array}{l}\text { Transition from light } \\
\text { to dark phase }\end{array}$ \\
\hline
\end{tabular}

\section{EPILEPSY INFLUENCES SLEEP AND CIRCADIAN RHYTHM IN ANIMAL MODELS}

\section{Epilepsy Influences Sleep in Kindling Models}

Epileptic seizures could also in turn alter sleep cycle or even circadian rhythm under the influence of epileptogenic pathology. Many studies provided evidence on the altered sleep activities caused by epileptic seizures. The influence of epileptic seizures on sleep-wakefulness was first reported in kindling models of epilepsy. Since 1980s, studies performed on kindling rats or cats reported that REM sleep activities were inhibited by electricalstimulation induced seizures (45-47). In 1998, however, Raol and Meti performed a systematic study about sleep activities in amygdaloid kindled rats and reported contradictory results. They found that stage 5 seizures could increase the duration of deep slow-wave sleep (SWS) and decrease the duration of both the NREM sleep and wakefulness (48). The discrepancy might be due to the different time of day when stimulations were given, just as Yi et al.s reported on amygdala kindling seizures. Kindling stimulation given at the beginning of the light phase decreased both SWS and REM sleep, while kindling stimulation given at the dark phase increased SWS but had no effect on REM sleep (49).

\section{Epilepsy Influences Sleep in Chronic TLE Model}

In chronic TLE models, indisputable results have presented the altered sleep activities. By analyzing $6 \mathrm{~h}$ long (6-12 a.m.) sleep architecture in rats 15 weeks after electrical stimulation induced SE. Bastlund et al. found an increase in the average time spent in wakefulness, and a decrease in the time spent in paradoxical sleep (50). A later study further analyzed distribution of sleepwake phases during $24 \mathrm{~h}$ in pilocarpine treated rats. The epileptic 
rats showed reduction of attentive wakefulness concomitant with increased SWS (51).

\section{Epilepsy Influences Sleep in Genetic Epileptic Model}

The altered sleep architecture is also found in several genetic epileptic models. Just as in WAG/Rij rats with spontaneous absence seizures, like TLE models, both NREM sleep and the sleep cycle were disrupted by epileptic activities (52). In Kcna1-null mice with SRS, durations of both NREM and REM sleep was less than those in WT mice (53). Meanwhile, in a mouse genetical mouse model of Dravet syndrome (DS), a rare epilepsy syndrome, Kalume et al. reported sleep impairment in DS mice as well, including reduced delta power and sleep spindles and increased brief wakefulness in NREM sleep (54).

In brief, epileptic activities undoubtedly influence the architecture of both sleep and wakefulness. Different animal models may show contradictory results, probably due to the diverse brain regions involved in epileptogenesis, which may affect the circadian activities in different ways. The data from animal studies reproduce many relevant features observed in clinical patients and thus highlight the role of these models in studying sleep dysfunction in epilepsy.

\section{Epilepsy Influences Other Type of Circadian Rhythm}

Besides sleep activities, the influence of epileptic seizures on other circadian activities has also been reported. In 2001, by using radio telemetry as a measurement of the temperature on hippocampal kindled rats, Quigg et al. demonstrated that electrically-induced seizures shifted the circadian temperature rhythms (CRT) which was different from the typical lightinduced phase shifts. In their study, the CRT in the first postictal $24 \mathrm{~h}$ were more complex and polyrhythmic than preictal conditions (55). As proposed by Smith et al., seizures could also affect the amplitude but not phase of the circadian clock. They applied a maximal electroconvulsive stimulation at different time-points of the day on hamsters. To their surprise, only the level of circadian locomotor activity but not the phase were significantly attenuated (56). Pilocarpine induced SE has also been reported to influence circadian rhythms. In mice treated by pilocarpine, the circadian EEG was transiently suppressed for several days after SE (33). A recent study further reported altered circadian rhythms in a model of sudden unexpected death in epilepsy. In this study, using passive infrared actigraphy to access circadian rest-activity patterns in epileptic rodents, Wallace et al. found disrupted diurnal and circadian rest-activity patterns characterized by prolonged circadian periods (53).

To conclude, animal models could reliably show an altered circadian rhythm and sleep activities as induced by epileptic seizures. The similarity to clinical conditions demonstrates that these models can be used to study the sleep disturbance and the disrupted circadian rhythm in epilepsy. Potential treatments for epilepsy-related sleeping disorders can be tested with these models. Valuable data obtained from these animal models would provide adequate grounding to help epileptic patients who suffer from sleep disorders as comorbidities.

\section{EPILEPSY-INDUCED CHANGES IN CIRCADIAN RHYTHM AND SLEEP ARCHITECTURE: THE POSSIBLE MECHANISMS}

\section{Altered Oscillatory Expression of Rhythm-Related Molecules in Epileptic Animal Models}

"Clock" proteins including BMAL (brain and muscle, ARNTlike) 1 and CLOCK (circadian locomotor output cycles kaput) in the hypothalamic suprachiasmatic nucleus (SCN) are autoregulators of circadian rhythm in mammals (57, 58). The feedback loops of these "clock" proteins lead to the establishment of circadian rhythms. For example, CLOCK and BMAL1 form heterodimers activate the transcription of downstream genes such as Period (Per1) and Cryptochrome (Cry1). BMAL1 reaches its peak of expression at mid-night, while the transcription of Pers and Crys (anti-phase to BMAL1 expression) reach their peaks during mid to late day. Pers and Crys along with other proteins form heteromultimeric complexes and directly abrogate the transcriptional activity of the CLOCK-BMAL1 complex, further leading to lowered Pers and Crys mRNA levels. This feedback loop along with others is the most important components of physiological day-and-night clock (59).

Several studies showed that mutations or deletion in these core proteins could impact circadian rhythms (60-62). In epilepsy, a study based on kindled mice showed that BMAL1 knockout not only eliminated the circadian difference of seizure susceptibility, but also directly lowered the seizure threshold (13). These results suggested the involvement of "clock" proteins in circadian epileptic activities and even epileptogenesis. Other studies on the oscillatory expressions of clock genes in epileptic animals further revealed its importance in a dynamic manner. In Kcna1 knockout epileptic mice, ketogenic diet was shown to improve the disturbed diurnal rhythmicity (63), which may be due to the circadian clock's phase shift mediated by SirT1 (a key factor involved in metabolism and life span, which interacts directly with CLOCK genes) (64). Further studies by Wallace et al. first provided direct evidence on the relationship of clock proteins and changed circadian rhythm in epileptic Kcna1-null mice. In their studies, all the epileptic mice manifested disrupted diurnal and circadian rest-activity patterns, and showed a reduced oscillatory expression of several clock proteins (Clock, Per1, and Per2) and diurnal Sirt1 mRNA in the anterior hypothalamus (53). The abnormal circadian rhythms in other neurogenerative diseases were also found to be closely related with an attenuation of oscillatory expressions of clock genes (65-67). Thus, the altered oscillation of clock genes is connected with altered circadian rhythms in epilepsy (Figure 2). 

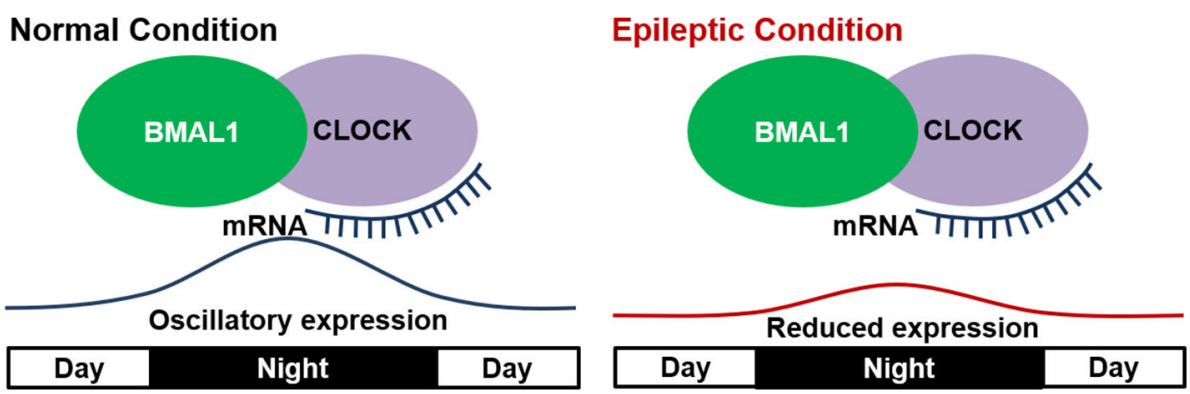

FIGURE 2 | Disrupted expression of "clock" genes in epilepsy. In the normal condition, "clock" genes including BMAL1 and CLOCK show a diurnal oscillatory expression with a peak at mid night. In epileptic condition, the oscillatory expression of "clock" genes is reduced and thus leads to altered circadian rhythm.

However, whether the conclusion can be generalized to epilepsies caused by various factors and pathologic processes needs further validation.

Besides "clock" genes, there are other molecules in the mammals' brain regulating circadian rhythms through a circadian pattern of expression. Study of the $24 \mathrm{~h}$ expression pattern of these molecules in epileptic animal models might provide clues to the circadian epileptic activities. Retinoic acid receptor-related orphan receptor alpha $(\operatorname{ROR} \alpha)$ is a member of a nuclear receptor superfamily and plays an essential role in regulating the circadian rhythm (68). In mammals, the ROR $\alpha$ is a crucial molecule in the regulation of BMAL1 expression. In hypothalamic $\mathrm{SCN}, \mathrm{ROR} \alpha$ shows an oscillatory expression, leading to the circadian pattern of BMAL1 expression (69), thereby directly influencing the circadian rhythm. In 2015, Rocha et al. attempted to study the daily pattern of $\mathrm{ROR} \alpha$ expression in chronic epileptic rats. They found that pilocarpine induced SE could decrease the mRNA expression of ROR $\alpha$ in the hippocampal area at both the light and dark phases, whether it be the acute and the silence (no SRS is present in animals) period, or at the $3 \mathrm{~h}$ point post the lightning-off in the chronic period (70). The evidence provides clues that acute SE could robustly influence the expression of $\operatorname{ROR} \alpha$, leading to a permanent alteration in its circadian expression pattern in the chronic period. The change might explain the altered circadian rhythms in epileptic models.

Melatonin is another important molecule synthesized and released in the pineal gland by a circadian manner, reaching a high level at night (71). Melatonin regulates circadian rhythms through an action on its membrane receptors $\left(\mathrm{MT}_{1}\right.$ and $\left.\mathrm{MT}_{2}\right)$ (72). Clinical studies have demonstrated that melatonin could alleviate sleep disturbance and reduce circadian alterations in epileptic patients (73-75); Moreover, one study on treatmentnaive active epileptic patients showed an increase of melatonin production in epileptic patients and a circadian pattern with a phase difference between patients and normal people (76). Rocha et al. studied the relationship between melatonin receptors and circadian changes in pilocarpine treated rats. They examined the $24 \mathrm{~h}$ profile of mRNA and protein expression of $\mathrm{MT}_{1}$ and $\mathrm{MT}_{2}$ receptor in different phases of pilocarpine models. In the chronic phase during which rats expressed SRS and an altered circadian rhythm, mRNA expression levels of both receptors return to levels close to control, however, presenting a different daily profile (77). In detail, MT1 receptor mRNA expression only decreased in the zeitgeber time point (ZT) 0 which is the transition phase of the light/dark cycle, and MT2 receptor mRNA expression increased at nighttime (ZT18). These biochemical results in animals revealed an altered expression of circadian rhythm related molecules in the chronic phase of epileptic models, which further suggested a close relationship between these molecules and the altered circadian rhythm in epilepsy. However, systematic experiments employing various intervention strategies along with detailed behavioral recordings are still needed.

\section{Involvement of Other Non-Rhythmic-Related Molecules in Epileptic Animal Models}

Neuroinflammation is widely involved in many neurological conditions including sleeping activities (78). Interleukin-1 $\beta$ (IL$1 \beta)$, one of the most important neuroinflammatory cytokines, is reported to be closely related with epiletogenesis according to numerous studies (79-82). In the epileptic brain, seizures upregulated the concentration level of IL- $1 \beta$ and the expression of IL-1 receptors, which further contributed to epileptic seizures or other comorbidities (80). Besides, IL-1 $\beta$ has an divergent effect on NREM sleep with different doses $(83,84)$. Therefore, IL-1 $\beta$ may mediate the epilepsy-induced sleep disturbances in epileptic patients. Yi et al. firstly revealed the crucial role of IL- $1 \beta$ and IL-1 $\beta$ receptor in epilepsy-induced sleep disruption. They performed kindling stimulation at the onset of dark phase, when SWS was induced along with an increased IL-1 $\beta$ mRNA expression in the brain. Administration of IL- $1 \beta$ receptor antagonist (IL-1ra) blocked the SWS induced by kindling (49). The involvement of IL-1 $\beta$ in an altered sleep architecture in epilepsy is further verified by Huang et al. They performed amygdaloid kindling stimulation at the particular ZT13 in both IL-1 $\beta$ receptor type 1 (IL-1R) KO mice and wildtype (WT) mice. In WT mice, kindling stimulation at ZT13 significantly enhanced NREM sleep, contrary to that observed in IL-1R KO mice (85). Yet no difference of seizure susceptibility between WT and KO mice were found. In consideration that changed IL-1 $\beta$ levels could directly affect seizure susceptibility, whether the involvement of 
IL-1 $\beta$ in epilepsy-induced sleep disruption is caused by its direct effect on seizures needs further investigation.

\section{Hypothalamic and Thalamic Pathology Underlies Changed Sleep Architecture in Epileptic Models}

The ascending arousal system is governed by neural pathways originating from well-defined cell groups in specific regions. The pathway has two branches, the first originating from hypothalamic suprachiasmatic nucleus ( $\mathrm{SCN})$, which is the crucial region in the modulation of circadian rhythms (86). Photic inputs are received in the SCN, which further convey the timing information by transcription-translation autoregulatory feedback loop of "clock" proteins, thereby affecting cellular functions including excitability (87). Then the information is outputted through the monoaminergic neurons of hypothalamic SCN to downstream nucleus such as cerebral cortex, which forms the ascending arousal system in the brain $(88,89)$. Evidence from animals demonstrated that hypothalamus lesions could directly induce long-lasting sleepiness or even somnolence $(90,91)$. Meanwhile, the endogenous hypothalamic dysfunctions were reported in epilepsy (92-95). Therefore, the hypothalamic pathology in epilepsy might result in disturbances of sleep and circadian rhythms. Sanabria et al. examined light induced Fos-protein expression in the SCN of the hypothalamus in epileptic rats, and the Fos-like immunoreactivity induced by photic stimulation was significantly reduced in chronic epileptic rats (96). Those results indicate that in chronic epileptic rats, light induced response was altered in the hypothalamus, which might reflect altered circadian rhythms. In 1999, Quigg et al. further reported the change of circadian rhythm of temperature (CRT) in epileptic animals, which was associated with a decreased neuronal density in anterior and posterior hypothalamus (97). A further study by Bastlund et al. confirmed the hypothalamic pathology in epileptic rats which showed a changed sleep architecture (50). They revealed that spontaneous epileptic rats following electrical stimulation induced SE showed a high percentage of seizures at sleep, which might be associated with neuronal cell loss in the dorsomedial hypothalamus.

Besides hypothalamic pathway, another ascending arousal pathway is controlled by thalamus. The crucial thalamic nuclei such as the reticular nucleus of the thalamus (RNT) has a role in gating wakefulness (98). Neural activities in some specific regions of the thalamus governs sleep activities (99, 100). Abnormal neural activities caused by epileptogenic pathology might thus result in sleep impairment. In 2015, Kalume et al. uncovered the reduced excitability in RNT interneurons in an epileptic mouse model with DS, and reported its association with sleep impairments (54). In their study, mice with DS, a common childhood-onset epilepsy syndrome, displayed an abnormal sleep architecture depending on activities of inhibitory GABAergic neurons in RNT. Reduced Nav current in the GABAergic RNT neurons led to the reduced rebound neural firing following hyperpolarization, which resulted in the disturbance of sleep architecture.

All those previous studies unveiled an evident association between hypothalamus and thalamus abnormalities and the

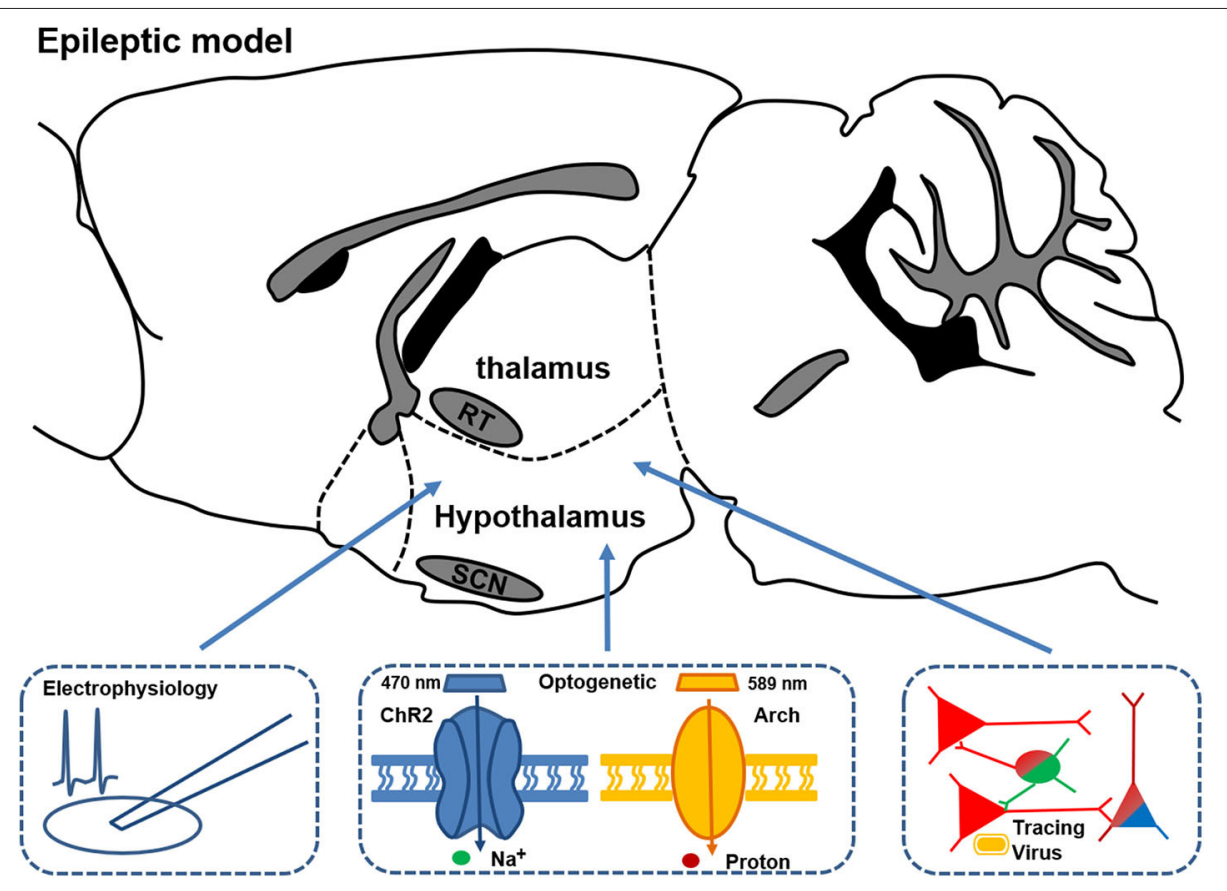

FIGURE 3 | Schematic of the circuitry experiments in thalamus and hypothalamus for studying the mechanisms of changed circadian rhythm and sleep in epileptic models. Combined multifaceted techniques including electrophysiology recording, optogenetics, and viral tracing can help to reveal the possible circuitry mechanism and provide potential precise treatment targets for disrupted circadian rhythm and sleep in epilepsy. 
altered circadian rhythm or sleep disturbance in animal models of epilepsy. Nevertheless, how the pathological hypothalamus or thalamus, along with the related neural circuits, contribute to the disturbance in sleep and circadian rhythms requires further investigation (Figure 3). Future studies, with an array of modern techniques, would enable a deeper understanding of the interaction between certain brain regions and circadian rhythm dysfunctions in epilepsy.

\section{CONCLUSIONS AND FUTURE PERSPECTIVES}

Cumulative evidence from animal studies have revealed a close relationship between circadian rhythm and epileptic activities. Evidence from animal studies, using models of chronic TLE, showed an altered temporal distribution of seizures similar to that observed in TLE patients, with a higher frequency of seizures in the light phase. On the other hand, seizure activities would also influence sleep-wake cycles, sleep architecture, and circadian rhythm. It may be attributed to an altered expression of rhythm-related or other non-rhythmic molecules, together with hypothalamus or thalamus pathologies. The advancement of technology and animal models gives animal studies a greater translational value. Therefore, animal models could be harnessed as useful tools to study the relationship between circadian rhythm and epilepsy.

Previously, most studies on the circadian distribution of epileptic seizures were performed on animal models of chronic TLE. More efforts should be spent on accurate seizure predictions based on circadian rhythms and also the development of closedlooped seizure control systems, which is currently studied by some ongoing clinical research (101). Animal studies, with its

\section{REFERENCES}

1. Allen CN. Circadian rhythms, diet, and neuronal excitability. Epilepsia. (2008) 49(Suppl. 8):124-6. doi: 10.1111/j.1528-1167.2008.01856.x

2. Quigg M. Circadian rhythms: interactions with seizures and epilepsy. Epilepsy Res. (2000) 42:43-55. doi: 10.1016/S0920-1211(00) 00157-1

3. Li S, Wang Y, Wang F, Hu LF, Liu CF. A new perspective for Parkinson's disease: circadian rhythm. Neurosci Bull. (2017) 33:6272. doi: 10.1007/s12264-016-0089-7

4. Khan S, Nobili L, Khatami R, Loddenkemper T, Cajochen C, Dijk DJ, et al. Circadian rhythm and epilepsy. Lancet Neurol. (2018) 17:1098108. doi: 10.1016/S1474-442230335-1

5. Baud MO, Kleen JK, Mirro EA, Andrechak JC, King-Stephens D, Chang EF, et al. Multi-day rhythms modulate seizure risk in epilepsy. Nat Commun. (2018) 9:88. doi: 10.1038/s41467-017-02577-y

6. Krook-Magnuson E, Armstrong C, Oijala M, Soltesz I. On-demand optogenetic control of spontaneous seizures in temporal lobe epilepsy. Nat Commun. (2013) 4:1376. doi: 10.1038/ncomms2376

7. Mormann F, Andrzejak RG, Elger CE, Lehnertz K. Seizure prediction: the long and winding road. Brain. (2007) 130:314-33. doi: 10.1093/brain/awl241

8. Kellaway P. Sleep and epilepsy. Epilepsia. (1985) 26(Suppl. 1):S1530. doi: 10.1111/j.1528-1157.1985.tb05720.x

9. Grone BP, Baraban SC. Animal models in epilepsy research: legacies and new directions. Nat Neurosci. (2015) 18:339-43. doi: 10.1038/nn.3934 translational value, can yet provide clues at the molecular, cellular and circuitry level. In particular, epilepsy is gradually considered as a disorder of abnormal neural networks (102). Although accumulating findings provide valuable clues at molecular and cellular levels, molecular and cellular mechanisms are still integrated at the level of brain networks, and the microcosmic perspective might restrict the understanding of epilepsy-induced circadian rhythm dysfunction. Delightfully, accumulating evidence revealed the crucial role of the hypothalamus and thalamus in circadian epileptic activities. Employment of advanced techniques including optogenetics, viral neuronal tracing et al. would allow a deeper understanding of circadian epileptic activities at the circular level. Individualized treatments for epilepsy-related circadian disturbances would also benefit from those animal studies as well.

In sum, animal studies could be well-harnessed when studying the relationship between circadian rhythm and epilepsy. Endeavors to bridge the gap between bench and bedside would greatly assist in the diagnosis, prediction and treatment of circadian epileptic activities.

\section{AUTHOR CONTRIBUTIONS}

CX and JY wrote the manuscript. YR, YW, and ZC edited the manuscript. All authors contributed to the article and approved the submitted version.

\section{FUNDING}

This work was supported by grants from the National Natural Science Foundation of China (81630098 and 81703480) and grants from the Fundamental Research Funds for the Central Universities (2019QNA5001).
10. Cederroth CR, Albrecht U, Bass J, Brown SA, Dyhrfjeld-Johnsen J, Gachon F, et al. Medicine in the fourth dimension. Cell Metab. (2019) 30:23850. doi: 10.1016/j.cmet.2019.06.019

11. Chellappa SL, Gaggioni G, Ly JQ, Papachilleos S, Borsu C, Brzozowski A, et al. Circadian dynamics in measures of cortical excitation and inhibition balance. Sci Rep. (2016) 6:33661. doi: 10.1038/srep33661

12. Calvo JM, Alvarado R, Briones R, Paz C, Fernandez-Guardiola A. Amygdaloid kindling during rapid eye movement (REM) sleep in cats. Neurosci Lett. (1982) 29:255-9. doi: 10.1016/0304-394090326-3

13. Gerstner JR, Smith GG, Lenz O, Perron IJ, Buono RJ, Ferraro TN. BMAL1 controls the diurnal rhythm and set point for electrical seizure threshold in mice. Front Syst Neurosci. (2014) 8:121. doi: 10.3389/fnsys.2014.00121

14. Kumar P, Raju TR. Seizure susceptibility decreases with enhancement of rapid eye movement sleep. Brain Res. (2001) 922:299-304. doi: 10.1016/S0006-899303174-2

15. Shouse MN, Sterman MB. Acute sleep deprivation reduces amygdala-kindled seizure thresholds in cats. Exp Neurol. (1982) 78:716-27. doi: 10.1016/0014-488690086-3

16. Shouse $\mathrm{MN}$, Sterman MB, Hauri PJ, Belsito O. Sleep disruption with basal forebrain lesions decreases latency to amygdala kindling in cats. Electroencephalogr Clin Neurophysiol. (1984) 58:369-77. doi: 10.1016/0013-469490063-4

17. Shouse MN. Sleep deprivation increases susceptibility to kindled and penicillin seizure events during all waking and sleep states in cats. Sleep. (1988) 11:162-71. doi: 10.1093/sleep/11.2.162 
18. Vale NB, Leite JR. Decreased susceptibility to local anesthetics-induced convulsions after paradoxical sleep deprivation. Psychopharmacology. (1988) 94:138-40. doi: 10.1007/BF00735895

19. Drinkenburg WH, Coenen AM, Vossen JM, van Luijtelaar EL. Sleep deprivation and spike-wave discharges in epileptic rats. Sleep. (1995) 18:2526. doi: 10.1093/sleep/18.4.252

20. Unterberger I, Gabelia D, Prieschl M, Chea K, Hofer M, Hogl B, et al. Sleep disorders and circadian rhythm in epilepsy revisited: a prospective controlled study. Sleep Med. (2015) 16:237-42. doi: 10.1016/j.sleep.2014.09.021

21. Holley S, Whitney A, Kirkham FJ, Freeman A, Nelson L, Whitlingum G, et al. Executive function and sleep problems in childhood epilepsy. Epilepsy Behav. (2014) 37:20-5. doi: 10.1016/j.yebeh.2014.05.022

22. McNamara JO, Byrne MC, Dasheiff RM, Fitz JG. The kindling model of epilepsy: a review. Prog Neurobiol. (1980) 15:13959. doi: 10.1016/0301-008290006-4

23. Muller CJ, Bankstahl M, Groticke I, Loscher W. Pilocarpine vs. lithiumpilocarpine for induction of status epilepticus in mice: development of spontaneous seizures, behavioral alterations and neuronal damage. Eur J Pharmacol. (2009) 619:15-24. doi: 10.1016/j.ejphar.2009.07.020

24. Levesque $M$, Avoli $M$. The kainic acid model of temporal lobe epilepsy. Neurosci Biobehav Rev. (2013) 37:288799. doi: 10.1016/j.neubiorev.2013.10.011

25. Li Z, You Z, Li M, Pang L, Cheng J, Wang L. Protective effect of resveratrol on the brain in a rat model of epilepsy. Neurosci Bull. (2017) 33:27380. doi: 10.1007/s12264-017-0097-2

26. Cavalheiro EA, Leite JP, Bortolotto ZA, Turski WA, Ikonomidou C, Turski L. Long-term effects of pilocarpine in rats: structural damage of the brain triggers kindling and spontaneous recurrent seizures. Epilepsia. (1991) 32:778-82. doi: 10.1111/j.1528-1157.1991.tb05533.x

27. Quigg M, Straume M, Menaker M, Bertram EH III. Temporal distribution of partial seizures: comparison of an animal model with human partial epilepsy. Ann Neurol. (1998) 43:748-55. doi: 10.1002/ana.410430609

28. Quigg M, Clayburn H, Straume M, Menaker M, Bertram EH III. Effects of circadian regulation rest-activity state on spontaneous seizures in a rat model of limbic epilepsy. Epilepsia. (2000) 41:502-9. doi: 10.1111/j.1528-1157.2000.tb00202.x

29. Tchekalarova J, Pechlivanova D, Itzev D, Lazarov N, Markova P, Stoynev A. Diurnal rhythms of spontaneous recurrent seizures and behavioral alterations of wistar and spontaneously hypertensive rats in the kainate model of epilepsy. Epilepsy Behav. (2010) 17:23-32. doi: 10.1016/j.yebeh.2009.11.001

30. Sedigh-Sarvestani M, Thuku GI, Sunderam S, Parkar A, Weinstein SL, Schiff SJ, et al. Rapid eye movement sleep and hippocampal theta oscillations precede seizure onset in the tetanus toxin model of temporal lobe epilepsy. $J$ Neurosci. (2014) 34:1105-14. doi: 10.1523/JNEUROSCI.3103-13.2014

31. Hellier JL, Dudek FE. Spontaneous motor seizures of rats with kainateinduced epilepsy: effect of time of day and activity state. Epilepsy Res. (1999) 35:47-57. doi: 10.1016/S0920-121100127-2

32. Raedt R, Van Dycke A, Van Melkebeke D, De Smedt T, Claeys P, Wyckhuys $\mathrm{T}$, et al. Seizures in the intrahippocampal kainic acid epilepsy model: characterization using long-term video-EEG monitoring in the rat. Acta Neurol Scand. (2009) 119:293-303. doi: 10.1111/j.1600-0404.2008.01108.x

33. Pitsch J, Becker AJ, Schoch S, Muller JA, de Curtis M, Gnatkovsky V. Circadian clustering of spontaneous epileptic seizures emerges after pilocarpine-induced status epilepticus. Epilepsia. (2017) 58:1159-71. doi: 10.1111/epi.13795

34. Bajorat R, Wilde M, Sellmann T, Kirschstein T, Kohling R. Seizure frequency in pilocarpine-treated rats is independent of circadian rhythm. Epilepsia. (2011) 52:e118-22. doi: 10.1111/j.1528-1167.2011.03200.x

35. Stewart LS, Bercovici E, Shukla R, Serbanescu I, Persad V, Mistry N, et al. Daily rhythms of seizure activity and behavior in a model of atypical absence epilepsy. Epilepsy Behav. (2006) 9:564-72. doi: 10.1016/j.yebeh.2006.08.019

36. Stewart LS, Nylen KJ, Persinger MA, Cortez MA, Gibson KM, Snead OC III. Circadian distribution of generalized tonic-clonic seizures associated with murine succinic semialdehyde dehydrogenase deficiency, a disorder of GABA metabolism. Epilepsy Behav. (2008) 13:290-4. doi: 10.1016/j.yebeh.2008.04.012
37. Cash CD, Maitre M, Mandel P. Purification from human brain and some properties of two NADPH-linked aldehyde reductases which reduce succinic semialdehyde to 4-hydroxybutyrate. J Neurochem. (1979) 33:116975. doi: 10.1111/j.1471-4159.1979.tb05261.x

38. Gibson KM, Christensen E, Jakobs C, Fowler B, Clarke MA, Hammersen $\mathrm{G}$, et al. The clinical phenotype of succinic semialdehyde dehydrogenase deficiency (4-hydroxybutyric aciduria): case reports of 23 new patients. Pediatrics. (1997) 99:567-74. doi: 10.1542/peds.99.4.567

39. Baxter P. Epilepsy and sleep. Dev Med Child Neurol. (2005) 47:723. doi: 10.1017/S0012162205001519

40. van Campen JS, Valentijn FA, Jansen FE, Joels M, Braun KP. Seizure occurrence and the circadian rhythm of cortisol: a systematic review. Epilepsy Behav. (2015) 47:132-7. doi: 10.1016/j.yebeh.2015.04.071

41. Gurkas E, Serdaroglu A, Hirfanoglu T, Kartal A, Yilmaz U, Bilir E. Sleepwake distribution and circadian patterns of epileptic seizures in children. Eur J Paediatr Neurol. (2016) 20:549-54. doi: 10.1016/j.ejpn.2016.04.004

42. Loddenkemper T, Vendrame M, Zarowski M, Gregas M, Alexopoulos AV, Wyllie E, et al. Circadian patterns of pediatric seizures. Neurology. (2011) 76:145-53. doi: 10.1212/WNL.0b013e318206ca46

43. Herman ST, Walczak TS, Bazil CW. Distribution of partial seizures during the sleep-wake cycle: differences by seizure onset site. Neurology. (2001) 56:1453-9. doi: 10.1212/WNL.56.11.1453

44. Crespel A, Coubes P, Baldy-Moulinier M. Sleep influence on seizures and epilepsy effects on sleep in partial frontal and temporal lobe epilepsies. Clin Neurophysiol. (2000) 111(Suppl. 2):S54-9. doi: 10.1016/S1388-245700402-8

45. Gigli GL, Gotman J. Effects of seizures, kindling, and carbamazepine on sleep organization in cats. Epilepsia. (1992) 33:14-22. doi: 10.1111/j.1528-1157.1992.tb02277.x

46. Stone WS, Gold PE. Amygdala kindling effects on sleep and memory in rats. Brain Res. (1988) 449:135-40. doi: 10.1016/0006-899391031-1

47. Shouse MN. Sleep disorders in kindled cats differ according to the timing of polygraphic recordings and of seizures in the sleep-wake cycle. Exp Neurol. (1987) 96:158-62. doi: 10.1016/0014-488690177-4

48. Raol YH, Meti BL. Sleep-wakefulness alterations in amygdala-kindled rats. Epilepsia. (1998) 39:1133-7. doi: 10.1111/j.1528-1157.1998.tb01303.x

49. Yi PL, Tsai CH, Lin JG, Lee CC, Chang FC. Kindling stimuli delivered at different times in the sleep-wake cycle. Sleep. (2004) 27:203-12. doi: 10.1093/sleep/27.2.203

50. Bastlund JF, Jennum P, Mohapel P, Penschuck S, Watson WP. Spontaneous epileptic rats show changes in sleep architecture and hypothalamic pathology. Epilepsia. (2005) 46:934-8. doi: 10.1111/j.1528-1167.2005.63204.x

51. Matos G, Tsai R, Baldo MV, de Castro I, Sameshima K, Valle AC. The sleep-wake cycle in adult rats following pilocarpine-induced temporal lobe epilepsy. Epilepsy Behav. (2010) 17:324-31. doi: 10.1016/j.yebeh.2009.11.015

52. van Luijtelaar G, Bikbaev A. Midfrequency cortico-thalamic oscillations and the sleep cycle: genetic, time of day and age effects. Epilepsy Res. (2007) 73:259-65. doi: 10.1016/j.eplepsyres.2006.11.002

53. Wallace E, Wright S, Schoenike B, Roopra A, Rho JM, Maganti RK. Altered circadian rhythms and oscillation of clock genes and sirtuin 1 in a model of sudden unexpected death in epilepsy. Epilepsia. (2018) 59:152739. doi: 10.1111/epi.14513

54. Kalume F, Oakley JC, Westenbroek RE, Gile J, de la Iglesia HO, Scheuer $\mathrm{T}$, et al. Sleep impairment and reduced interneuron excitability in a mouse model of Dravet Syndrome. Neurobiol Dis. (2015) 77:14154. doi: 10.1016/j.nbd.2015.02.016

55. Quigg M, Straume M, Smith T, Menaker M, Bertram EH. Seizures induce phase shifts of rat circadian rhythms. Brain Res. (2001) 913:1659. doi: 10.1016/S0006-899302780-9

56. Smith VM, Baserman JN, Hagel K, Teskey GC, Antle MC. A single generalized seizure alters the amplitude, but not phase, of the circadian activity rhythm of the hamster. Chronobiol Int. (2009) 26:1-13. doi: 10.1080/07420520802694103

57. Kondratov RV, Chernov MV, Kondratova AA, Gorbacheva VY, Gudkov AV, Antoch MP. BMAL1-dependent circadian oscillation of nuclear CLOCK: posttranslational events induced by dimerization of transcriptional activators of the mammalian clock system. Genes Dev. (2003) 17:192132. doi: 10.1101/gad.1099503 
58. Schibler U, Sassone-Corsi P. A web of circadian pacemakers. Cell. (2002) 111:919-22. doi: 10.1016/S0092-867401225-4

59. Lowrey PL, Takahashi JS. Mammalian circadian biology: elucidating genome-wide levels of temporal organization. Annu Rev Genomics Hum Genet. (2004) 5:407-41. doi: 10.1146/annurev.genom.5.061903.175925

60. Ko CH, Takahashi JS. Molecular components of the mammalian circadian clock. Hum Mol Genet. (2006) 15:R271-7. doi: 10.1093/hmg/ddl207

61. Jones CR, Huang AL, Ptacek LJ, Fu YH. Genetic basis of human circadian rhythm disorders. Exp Neurol. (2013) 243:2833. doi: 10.1016/j.expneurol.2012.07.012

62. Allada R, Emery P, Takahashi JS, Rosbash M. Stopping time: the genetics of fly and mouse circadian clocks. Ann Rev Neurosci. (2001) 24:1091119. doi: 10.1146/annurev.neuro.24.1.1091

63. Fenoglio-Simeone KA, Wilke JC, Milligan HL, Allen CN, Rho JM, Maganti RK. Ketogenic diet treatment abolishes seizure periodicity and improves diurnal rhythmicity in epileptic Kcna1-null mice. Epilepsia. (2009) 50:202734. doi: 10.1111/j.1528-1167.2009.02163.x

64. Genzer Y, Dadon M, Burg C, Chapnik N, Froy O. Ketogenic diet delays the phase of circadian rhythms and does not affect AMP-activated protein kinase (AMPK) in mouse liver. Mol Cell Endocrinol. (2015) 417:12430. doi: $10.1016 /$ j.mce.2015.09.012

65. Duncan MJ, Smith JT, Franklin KM, Beckett TL, Murphy MP, St Clair DK, et al. Effects of aging and genotype on circadian rhythms, sleep, and clock gene expression in APPxPS1 knock-in mice, a model for Alzheimer's disease. Exp Neurol. (2012) 236:249-58. doi: 10.1016/j.expneurol.2012.05.011

66. Bonaconsa M, Colavito V, Pifferi F, Aujard F, Schenker E, Dix S, et al. Cell clocks and neuronal networks: neuron ticking and synchronization in aging and aging-related neurodegenerative disease. Curr Alzheimer Res. (2013) 10:597-608. doi: 10.2174/15672050113109990004

67. Wang X, Wang L, Yu Q, Xu Y, Zhang L, Zhao X, et al. Alterations in the expression of per1 and per2 induced by abeta31-35 in the suprachiasmatic nucleus, hippocampus, and heart of C57BL/6 mouse. Brain Res. (2016) 1642:51-8. doi: 10.1016/j.brainres.2016.03.026

68. Solt LA, Burris TP. Action of RORs and their ligands in (patho)physiology. Trends Endocrinol Metab. (2012) 23:619-27. doi: 10.1016/j.tem.2012. 05.012

69. Guillaumond F, Dardente H, Giguere V, Cermakian N. Differential control of Bmall circadian transcription by REV-ERB and ROR nuclear receptors. J Biol Rhythms. (2005) 20:391-403. doi: 10.1177/07487304052 77232

70. Rocha AK, de Lima E, do Amaral FG, Peres R, Cipolla-Neto J, Amado D. Pilocarpine-induced epilepsy alters the expression and daily variation of the nuclear receptor RORalpha in the hippocampus of rats. Epilepsy Behav. (2016) 55:38-46. doi: 10.1016/j.yebeh.2015.11.026

71. Stehle JH, Saade A, Rawashdeh O, Ackermann K, Jilg A, Sebesteny T, et al. A survey of molecular details in the human pineal gland in the light of phylogeny, structure, function and chronobiological diseases.J Pineal Res. (2011) 51:17-43. doi: 10.1111/j.1600-079X.2011.00856.x

72. Karasek M, Winczyk K. Melatonin in humans. J Physiol Pharmacol. (2006) 57(Suppl. 5):19-39.

73. Fauteck J, Schmidt H, Lerchl A, Kurlemann G, Wittkowski W. Melatonin in epilepsy: first results of replacement therapy and first clinical results. Biol Signals Recept. (1999) 8:105-10. doi: 10.1159/000014577

74. Peled N, Shorer Z, Peled E, Pillar G. Melatonin effect on seizures in children with severe neurologic deficit disorders. Epilepsia. (2001) 42:120810. doi: 10.1046/j.1528-1157.2001.28100.x

75. Coppola G, Iervolino G, Mastrosimone M, La Torre G, Ruiu F, Pascotto A. Melatonin in wake-sleep disorders in children, adolescents and young adults with mental retardation with or without epilepsy: a doubleblind, cross-over, placebo-controlled trial. Brain Dev. (2004) 26:3736. doi: 10.1016/j.braindev.2003.09.008

76. Schapel GJ, Beran RG, Kennaway DL, McLoughney J, Matthews CD. Melatonin response in active epilepsy. Epilepsia. (1995) 36:75-8. doi: 10.1111/j.1528-1157.1995.tb01669.x

77. Rocha A, de Lima E, Amaral F, Peres R, Cipolla-Neto J, Amado D. Altered MT1 and MT2 melatonin receptors expression in the hippocampus of pilocarpine-induced epileptic rats. Epilepsy Behav. (2017) 71:2334. doi: 10.1016/j.yebeh.2017.01.020
78. Xanthos DN, Sandkuhler J. Neurogenic neuroinflammation: inflammatory CNS reactions in response to neuronal activity. Nat Rev Neurosci. (2014) 15:43-53. doi: 10.1038/nrn3617

79. Feng B, Tang Y, Chen B, Xu C, Wang Y, Dai Y, et al. Transient increase of interleukin-1beta after prolonged febrile seizures promotes adult epileptogenesis through long-lasting upregulating endocannabinoid signaling. Sci Rep. (2016) 6:21931. doi: 10.1038/srep21931

80. Rijkers K, Majoie HJ, Hoogland G, Kenis G, De Baets M, Vles JS. The role of interleukin-1 in seizures and epilepsy: a critical review. Exp Neurol. (2009) 216:258-71. doi: 10.1016/j.expneurol.2008.12.014

81. Ravizza T, Vezzani A. Status epilepticus induces time-dependent neuronal and astrocytic expression of interleukin-1 receptor type I in the rat limbic system. Neuroscience. (2006) 137:3018. doi: 10.1016/j.neuroscience.2005.07.063

82. Tao AF, Xu ZH, Chen B, Wang Y, Wu XH, Zhang J, et al. The proinflammatory cytokine interleukin-1beta is a key regulatory factor for the postictal suppression in mice. CNS Neurosci Ther. (2015) 21:64250. doi: $10.1111 / \mathrm{cns} .12416$

83. Alam MN, McGinty D, Bashir T, Kumar S, Imeri L, Opp MR, et al. Interleukin-1beta modulates state-dependent discharge activity of preoptic area and basal forebrain neurons: role in sleep regulation. Eur J Neurosci. (2004) 20:207-16. doi: 10.1111/j.1460-9568.2004.03469.x

84. Opp MR, Obal F Jr., Krueger JM. Interleukin 1 alters rat sleep: temporal and dose-related effects. Am J Physiol. (1991) 260:R528. doi: 10.1152/ajpregu.1991.260.1.R52

85. Huang TR, Jou SB, Chou YJ, Yi PL, Chen CJ, Chang FC. Interleukin-1 receptor (IL-1R) mediates epilepsy-induced sleep disruption. BMC Neurosci. (2016) 17:74. doi: 10.1186/s12868-016-0309-0

86. Saper CB, Scammell TE, Lu J. Hypothalamic regulation of sleep and circadian rhythms. Nature. (2005) 437:1257-63. doi: 10.1038/nature04284

87. Kuhlman SJ, McMahon DG. Rhythmic regulation of membrane potential and potassium current persists in SCN neurons in the absence of environmental input. Eur J Neurosci. (2004) 20:1113-7. doi: 10.1111/j.1460-9568.2004.03555.x

88. Saper CB, Chou TC, Scammell TE. The sleep switch: hypothalamic control of sleep and wakefulness. Trends Neurosci. (2001) 24:72631. doi: $10.1016 / \mathrm{S} 0166-223602002-6$

89. Xiao F, Lu C, Zhao D, Zou Q, Xu L, Li J, et al. Independent component analysis and graph theoretical analysis in patients with narcolepsy. Neurosci Bull. (2019) 35:743-55. doi: 10.1007/s12264-018-0307-6

90. Anand BK. Somnolence caused by destructive lesions in the hypothalamus in cat. Ind J Med Res. (1955) 43:195-9.

91. Gerashchenko D, Blanco-Centurion C, Greco MA, Shiromani PJ. Effects of lateral hypothalamic lesion with the neurotoxin hypocretin-2-saporin on sleep in long-evans rats. Neuroscience. (2003) 116:223-35. doi: 10.1016/S0306-452200575-4

92. Soussi R, Boulland JL, Bassot E, Bras H, Coulon P, Chaudhry FA, et al. Reorganization of supramammillary-hippocampal pathways in the rat pilocarpine model of temporal lobe epilepsy: evidence for axon terminal sprouting. Brain Struct Funct. (2015) 220:2449-68. doi: 10.1007/s00429-014-0800-2

93. Jo HJ, Kenney-Jung DL, Balzekas I, Welker KM, Jones DT, Croarkin PE, et al. Relationship between seizure frequency and functional abnormalities in limbic network of medial temporal lobe epilepsy. Front Neurol. (2019) 10:488. doi: 10.3389/fneur.2019.00488

94. Wulsin AC, Solomon MB, Privitera MD, Danzer SC, Herman JP. Hypothalamic-pituitary-adrenocortical axis dysfunction in epilepsy. Physiol Behav. (2016) 166:22-31. doi: 10.1016/j.physbeh.2016.05.015

95. Scholly J, Valenti MP, Staack AM, Strobl K, Bast T, Kehrli P, et al. Hypothalamic hamartoma: is the epileptogenic zone always hypothalamic? Arguments for independent (third stage) secondary epileptogenesis. Epilepsia. (2013) 54(Suppl. 9):123-8. doi: 10.1111/epi.12456

96. Sanabria ER, Scorza FA, Bortolotto ZA, Calderazzo-Filho LS, Cavalheiro EA. Disruption of light-induced c-Fos immunoreactivity in the suprachiasmatic nuclei of chronic epileptic rats. Neurosci Lett. (1996) 216:105-8. doi: 10.1016/0304-394013020-2

97. Quigg M, Clayburn H, Straume M, Menaker M, Bertram EH III. Hypothalamic neuronal loss altered circadian rhythm of temperature in 
a rat model of mesial temporal lobe epilepsy. Epilepsia. (1999) 40:168896. doi: 10.1111/j.1528-1157.1999.tb01585.x

98. McCormick DA. Cholinergic and noradrenergic modulation of thalamocortical processing. Trends Neurosci. (1989) 12:21521. doi: 10.1016/0166-2236(89)90125-2

99. Gent TC, Bassetti C, Adamantidis AR. Sleep-wake control and the thalamus. Curr Opin Neurobiol. (2018) 52:188-97. doi: 10.1016/j.conb.2018. 08.002

100. Jan JE, Reiter RJ, Wasdell MB, Bax M. The role of the thalamus in sleep, pineal melatonin production, and circadian rhythm sleep disorders. J Pineal Res. (2009) 46:1-7. doi: 10.1111/j.1600-079X.2008. 00628.x

101. Karoly PJ, Ung H, Grayden DB, Kuhlmann L, Leyde K, Cook MJ, et al. The circadian profile of epilepsy improves seizure forecasting. Brain. (2017) 140:2169-82. doi: 10.1093/brain/awx173
102. Wang Y, Chen Z. An update for epilepsy research and antiepileptic drug development: toward precise circuit therapy. Pharmacol Ther. (2019) 201:77-93. doi: 10.1016/j.pharmthera.2019.05.010

Conflict of Interest: The authors declare that the research was conducted in the absence of any commercial or financial relationships that could be construed as a potential conflict of interest.

Copyright $\odot 2020 \mathrm{Xu}, \mathrm{Yu}, \mathrm{Ruan}$, Wang and Chen. This is an open-access article distributed under the terms of the Creative Commons Attribution License (CC BY). The use, distribution or reproduction in other forums is permitted, provided the original author(s) and the copyright owner(s) are credited and that the original publication in this journal is cited, in accordance with accepted academic practice. No use, distribution or reproduction is permitted which does not comply with these terms. 